Rabaska

Revue d'ethnologie de l'Amérique française

\title{
Laboratoire de muséologie et d'ingénierie de la culture (Université Laval)
}

\section{Jean-François Gauvin}

Volume 17, 2019

URI : https://id.erudit.org/iderudit/1066054ar

DOI : https://doi.org/10.7202/1066054ar

Aller au sommaire du numéro

Éditeur(s)

Société québécoise d'ethnologie

ISSN

1703-7433 (imprimé)

1916-7350 (numérique)

Découvrir la revue

Citer ce document

Gauvin, J.-F. (2019). Laboratoire de muséologie et d'ingénierie de la culture (Université Laval). Rabaska, 17, 396-397. https://doi.org/10.7202/1066054ar d'utilisation que vous pouvez consulter en ligne.

https://apropos.erudit.org/fr/usagers/politique-dutilisation/ 


\section{Laboratoire de muséologie et d'ingénierie de la culture (LAMIC)}

Pavillon Casault, local 3645-Z

Université Laval

Québec (Québec)

Téléphone : (418) 656-2131, poste 402515

G1V 0A6

Courriel : jean-francois.gauvin@hst.ulaval.ca

Toile : www.flsh.ulaval.ca/chaire-museologie/lamic

\section{Activités en 2018-2019}

En poste à l'Université Laval depuis le $1^{\text {er }}$ mars 2018, on m'a chargé de la relance du Diplôme d'études supérieures spécialisées (DÉss) en muséologie et des activités du LAMIC, fondé en 2007 par Philippe Dubé et dirigé par lui pendant plus de dix ans. Pour cette année de relance du DÉss, nous avons recruté cinq étudiantes à temps complet et une étudiante à temps partiel. Nous prévoyons déjà une douzaine de nouveaux étudiants pour la prochaine année universitaire. Les cinq étudiantes finissantes ont fait leur stage d'été au sein de trois organisations muséales, soit le Monastère des Augustines, le Pôle culturel du monastère des Ursulines et le Musée national des beaux-arts du Québec, sur des sujets touchant à la médiation culturelle, aux expositions, et à la documentation et la conservation des collections. Le Déss en muséologie semble donc en voie de reprendre le rôle important qu'il a toujours joué dans la formation de la relève pour la grande région de Québec.

Le lancement officiel de la Chaire de leadership en enseignement en muséologie et mise en public (CLE) s'est déroulé au LAMIC le 23 janvier 2019, avec un discours inaugural de son titulaire. Plus d'une quarantaine de personnes y ont assisté. Il en fut de même le $1^{\mathrm{er}}$ mai suivant lors du vernissage de l'exposition des étudiantes du DÉss, intitulée Soigner le passé : un regard sur nos collections, mettant en vedette les riches collections de l'Université Laval. Le vernissage a été précédé d'une conférence donnée par Dániel Margócsy (Université de Cambridge) : «Iconic Vesalius : The Woodblocks of Fabrica and the Rise of Visual Studies ». Le LAMIC retrouve vie doucement et continue d'être un espace qui fait parler de lui. Par exemple, j'ai eu l'occasion de présenter ma vision future du laboratoire dans le cadre de la Semaine NumériQc, le 11 avril 2019. Cette visite du LAMIC et des autres laboratoires du pavillon Casault était organisée par l'Institut technologies de l'information et sociétés (ITIS). Finalement, le 20 juin dernier, lors du lancement de la programmation estivale du Pôle culturel du monastère des Ursulines, j'ai eu l'honneur de lancer officiellement le projet du Monastère 3D (en ligne), un projet numérique novateur commencé en 2011 et réalisé sous la direction générale de Philippe Dubé. Ce site web, en grande partie financé par le Programme d'investissement pour les expositions virtuelles du Musée virtuel du Canada, offre à l'internaute une exploration - une déambulation - virtuelle du monastère où sons et images viennent se juxtaposer pour nous faire découvrir un site unique en Amérique du Nord. Avec mon collègue Robert Faguy, directeur du Laboratoire des nouvelles technologies de l'image, du son et de la scène (LANTISS), nous tenterons au cours des prochaines années de générer des projets de recherche collaboratifs et de financer l'expansion nos activités.

Du côté de la recherche, avec mes collègues Laurier Turgeon, Yves Bergeron et Habib Saidi, nous entreprenons un projet de recherche de trois ans (subventionné par le CRSH) intitulé Pour une nouvelle gouvernance des musées : enjeux et perspec- 
tives. Dans ce contexte, trois étudiants ont entamé des études supérieures : Manon Joly fait une maîtrise sur les dispositifs numériques et le public adolescent dans les musées ; Bernard Niouly Nkaye amorce un doctorat sur la préservation du patrimoine photographique ancien (1880-1960) de la ville de Saint-Louis (Sénégal) au moyen du numérique ; et, en codirection avec Jocelyne Mathieu, une postdoctorante boursière du FRQSC, Laurence Provancher-Saint-Pierre, mènera en janvier 2020 un projet intitulé Les collections d'étude et le rôle du chercheur-collectionneur dans la définition, la diffusion et la transmission du patrimoine culturel : l'exemple de la collection Robert-Lionel-Séguin. Je tente activement de recruter d'autres étudiants au doctorat et au postdoctorat.

On m'a invité à participer à la rencontre Définir le musée, organisée par le Comité international pour la muséologie (ICOFOM), le 25 octobre 2018, à l'UQȦm; la nouvelle définition du musée sera dévoilée et votée au congrès de l'Icom cet automne à Kyoto. Enfin, je suis devenu un membre associé de la Chaire de recherche sur la gouvernance des musées et le droit de la culture de l'UQÀm, dont le titulaire est Yves Bergeron.

\section{Communications et publications}

Au cours de l'année 2018-2019, j'ai livré quatre communications : • «The Next Level of Play: How Cartesian Devils, Volcanos, and Quantum Toys Taught General Science at Harvard, 1730-1970», à la Cain conference intitulée Shaping Scientific Instrument Collections, tenue au Science History Institute, Philadelphie, 18-21 avril 2018 (cet exposé a été publié en ligne dans le Journal of the History of Collections : doi.org/10.1093/jhc/fhy033; 19 octobre 2018); « Silence, on touche! La promesse du matériel contre l'évanescence muséale», conférence d'ouverture au colloque Matérialité, esthétique et histoire des techniques : la collection François Lemai comme laboratoire, à l'Université Laval, Québec, 13-17 mai 2019; • «Les Musées (et collections) universitaires au Québec, quel avenir? », au colloque intitulé Frontières et dialogues interdisciplinaires des patrimoines, $87^{\circ}$ Congrès de l'ACFAS, Université du Québec en Outaouais, Gatineau, 28-29 mai 2019 ; et • «Réparation, restauration, exposition : la valeur des instruments disloqués dans les musées de sciences et de technologie», au colloque "Les Réparations, de la préhistoire à nos jours : cultures techniques et savoir-faire, à Paris (plusieurs lieux) les 26-27-28 juin 2019.

J'ai aussi publié l'article "Playing with Quantum Toys : Julian Schwinger's Measurement Algebra and the Material Culture of Quantum Mechanics Pedagogy at Harvard in the 1960s », dans Physics in Perspective, vol. 20, 2018, p. 8-42.

Pour suivre les activités de la Chaire (et du LAMIC), prière de consulter la page web suivante : www.flsh.ulaval.ca/chaire-museologie. 